\title{
LAPATERNIDAD ESPIRITUAL DEL SACERDOTE EN TIEMPOS DE TRIBULACIONES, SEGÚN EL MAESTRO ÁVILA
}

JUAN DEL Río MARTín ${ }^{1}$

DOI: https://doi.org/10.52039/seminarios.v57i201-202.334

«Muchos son los frentes y muy gastada está la cristiandad», esta descripción de la Iglesia del siglo XVI pertenece al apóstol, predicador, reformador y teólogo español san Juan de Ávila. La respuesta a tantos desafíos pasaba por la reforma del clero, porque «así como son los pastores de igual manera será la grey», de ahí que el sacerdote ante todo debía ser «hombre de Dios que gana hijos para Dios». El argumento de la paternidad espiritual es central en su pensamiento sobre el sacerdocio católico y eso hoy tiene mucha actualidad.

Han pasado cinco siglos y en el umbral del siglo XXI la «barca de Pedro» se ve sacudida por graves escándalos sexuales del clero, por una sociedad que vive ya de espalda a Dios y por una cultura que reniega de sus raíces cristianas. Al igual que en tiempos del apóstol de Andalucía, la Iglesia tiene que responder a difíciles retos, cuya superación pasa por la santidad del clero.

Al abordar este estudio no nos mueve ningún afán de arqueología espiritual o teológica, sino el convencimiento de que el Patrono del clero secular español, su figura y escritos, continúa siendo un Maestro para los sacerdotes que han de ejercer su ministerio en un mundo secularizado. Desde el principio decimos que nos situamos ante un tema clásico, de siempre, y que es urgente y necesaria su recuperación en la espiritualidad sacerdotal de hoy. De hecho, su relación con la vida afectiva es abordada en la Instrucción de la Congregación para la Educación Católica, que a este respecto dice: «el sacerdote, en efecto, representa sacramentalmente a Cristo Cabeza, Pastor y Esposo de la Iglesia. Por razón de esta configuración con Cristo, la vida toda del ministro sagrado debe estar animada por la entrega de su persona a la Iglesia y por la auténtica caridad pastoral. El candidato al ministerio ordenado debe, por tanto, alcanzar la madurez afectiva. Tal madurez lo capacitará para situarse en una relación correcta con hombres y mujeres, desarrollando en él un verdadero sentido de la paternidad espiritual en relación con la comunidad eclesial que le será confiada»².

1. Arzobispo Castrense de España. Doctor en Teología por la Pontificia Universidad Gregoriana con una tesis sobre la eclesiología en el pensamiento reformador de Juan de Ávila.

2. C.E.C., Sobre los criterios de discernimiento vocacional en relación con las personas de tendencias homosexuales antes de su admisión al Seminario y las Órdenes Sagradas, Ro- 
Nuestra reflexión se va a centrar en los elementos teológicos y espirituales de la paternidad sacerdotal como núcleo de la identidad sacerdotal según san Juan de Ávila. Damos por conocidos y asumidos los presupuestos de orden humano, psicológico y afectivo que están en la base de este tema y que serían objeto de otra exposición. Pero antes que nada, tengamos como «telón de fondo» esta breve comparación entre las dos épocas.

\section{Paralelismos eclesiales}

\section{Recordando la vida de nuestro Patrón}

San Juan de Ávila (1499? - 1569) nace en Almodóvar del Campo (Ciudad Real) y muere en la ciudad cordobesa de Montilla. Por sus venas corre sangre de nuevos cristianos. Estudia en Salamanca y Alcalá. Tiene profesores como Domingo de Soto en Artes y Juan de Medina en Teología. Heredero de muchas concepciones teológicas del Medievo y de los predicadores populares tales como Vicente Ferrer. Sin embargo, fue un hombre de vanguardia en su tiempo, que lee y recomienda la lectura de Erasmo, aunque con cautela, antiluterano convencido, pero que sabe llamar «hermanos conjuntos» a los que se separaron de Roma. Y por si fuera poco, debelador de los engaños de los alumbrados. Propulsor de la frecuencia de los sacramentos y de la lectura asidua de la Escritura. Amante de una espiritualidad litúrgica y de la oración mental. Será promotor de múltiples iniciativas docentes y catequéticas para elevar la cultura de «las gentes y eclesiásticos». Y como buen representante de la época no le faltará la faceta de inventor de física y mecánica ${ }^{3}$.

\section{La Iglesia del siglo XVI}

La Iglesia en que vivió el Apóstol de Andalucía es la que va del renacimiento a la reforma católica. En ella se debatía la lucha de una Iglesia que, anclada en muchas concepciones medievales, no estaba en sintonía con los deseos de reforma «in capite et in membris» que concilios, reyes, sacerdotes religiosos y fieles pedían desde mucho tiempo atrás. Las altas jerarquías: Papas, Obispos, y dignidades sacerdotales aparecían más unidas a los «negocios seculares» que a los oficios de predicación y santificación del pueblo de Dios, además de la abundan-

ma 2005, 1. Pastores dabo vobis afirma: «El sacerdote está llamado a ser imagen viva de Jesucristo Esposo de la Iglesia... Por tanto, está llamado a revivir en su vida espiritual el amor de Cristo Esposo con la Iglesia Esposa. Su vida debe estar iluminada y orientada también por este rasgo esponsal, que le pide ser testigo del amor de Cristo como Esposo», PDV 22.

3. Cf. García-VILloslada, R., «La figura del Beato Ávila», Manresa 17 (1945) 255ss; De LA FuENTE, A., «El Beato Ávila, alma de la verdadera reforma de la Iglesia española», Semana Avilista (1952) 231-250. 
cia de clérigos ignorantes, los tan conocidos «ordenados para Misas», y la relajación de las órdenes religiosas. Para el Apóstol de Andalucía, la increencia y todo tipo de males en los fieles derivan de la negligencia de los pastores, de quienes se apacientan a sí mismos, buscan sus intereses y no cuidan de sus ovejas. Sin la reforma del clero, es imposible la regeneración de la Iglesia.

En medio de este panorama, la Iglesia tiene que enfrentarse con los planteamientos del humanismo renacentista, con la doctrina dogmática y disciplinar que levantaba el «huracán de Lutero», como dice el P. García-Villoslada, junto con los diversos focos de alumbrados y el Nuevo Mundo que había que evangelizar. A esos males ¿Qué respuesta hubo entonces? Dice Herbert Jedin que la de «Trento vendría a significar una respuesta interesante pero tardía». Por ello, prestigiosos historiadores no dudarán en presentar a San Juan de Ávila como figura insigne de la verdadera reforma española marcada por el elemento espiritual que incide en el cambio de vida del clero y en la reforma de las estructuras, cuyo movimiento es de «adentro hacia fuera». Ciertamente que se adelanto a los tiempos y tuvo su importante repercusión en el aula conciliar de Trento y en la espiritualidad sacerdotal posterior. Un sacerdote que vivió tiempos de reformas, cambios culturales y concilio bastante similares a los nuestros, ha de dar mucha luz en la búsqueda de la identidad espiritual del sacerdote que ha de ejercer su ministerio en esta sociedad plural y secular del siglo XXI.

\section{El cambio cultural y su incidencia en el tema sacerdotal}

La vida y misión del sacerdote actual se desenvuelve en una cultura marcada por el nihilismo, el inmanentismo y el relativismo moral. Si en el siglo pasado el existencialismo se preguntaba ¿qué es el hombre? y para el marxismo lo importante era saber ¿para qué sirve el hombre? Sin embargo, con la caída del muro de Berlín en 1989 y la crisis ideológica, surge con fuerza la llamada postmodernidad donde ya no hay preguntas ni sobre Dios, ni sobre el hombre, ni interesa las respuestas de aquellas que despectivamente llama metarrelatos. Esta actitud supone la consagración del pensamiento de Nietzsche, tras constatar el fracaso de Marx y la superación del análisis freudiano. Todo ello ha dado origen a una sociedad no ya postcristiana, sino anticristiana, como lo demuestra el fenómeno de la cristianofobia tan abundante en los ambientes mediáticos occidentales y llegando a la persecución por el fanatismo radical islámico.

Hoy, la Iglesia se ve interpelada o amenazada por la autosuficiencia del tiempo moderno que trae consigo el secularismo y el laicismo exacerbados, intentando secar las raíces cristianas de nuestro pueblo. Es un intento de destruir las bases judeocristianas de la cultura occidental. Por otra parte, este «humus cultural» descristianizador ha entrado en algunos sectores pastorales, y el mismo sacerdocio católico es llevado con frecuencia a la «picota» en los medios de comunicación social. A esta situación, conocida de todos, hay que añadir que en nombre de un 
pluralismo religioso y de una tolerancia interesada se orqueste "una ingeniería social» para arrinconar al máximo la presencia social de la Iglesia Católica. Estos desafíos, repercuten en la vida personal y pastoral del sacerdote, que como se está viendo, afectas a su misma identidad. Sabemos que en una sociedad como la nuestra, aquellos colectivos que pierden sus raíces y su consistencia fundamental son atrapados por la mentalidad secularista dominante.

Los hechos pastorales hablan por sí solos. Ahí están los escándalos sexuales de clérigos, la continua sangría del abandono del sacerdocio, las faltas de energías y celo apostólico, la sequia vocacional que no se remonta. En fin, tantas cosas como están sucediendo. Surgen muchos interrogantes como estos: ¿Qué le pasa hoy al sacerdote católico? ¿Por qué esa «cruzada» mediática y cultural contra el celibato? ¿Es tanta la corrupción en la Iglesia o más bien hay «campaña» orquestada por los enemigos del cristianismo, que se aprovechan de los pecados y delitos de unos pocos? Todo esto y otros muchos elementos ponen de manifiesto la crisis de identidad sacerdotal de una parte del clero, de la cual todo el mundo habla en sentido descriptivo, pero son muy pocos los que se ocupan de decirnos en qué consiste el núcleo específico que configura esa identidad y cómo se ha de vivir en cualquier tiempo y lugar.

Lo primero que debemos tener presente es cómo en estos momentos actuales, las figuras o referencias al «padre, al maestro, al director de almas», están en crisis debido al tipo de sociedad y cultura que hemos descrito. Lo que hoy se cotiza es hablar de: «amigo, compañero, enseñante» que de alguna manera expresen horizontalidad en las relaciones y en los principios, quedando diluido cualquier elemento aglutinador o de autoridad. Es más, hablar de paternidad espiritual es para algunos como querer volver a concepciones paternalistas del ministerio sacerdotal que infantilizan a los fieles. Pues bien, nunca más lejos de la realidad porque aquellos que han abordado el tema de la paternidad espiritual sacerdotal han sido los santos y los místicos que son los más comprometidos con el pueblo y los que verdaderamente han llevado en el seno de la Iglesia la llamada «revolución de Dios» (Benedicto XVI).

Además, la revitalización de la vida cristiana pasa por la santidad de sus pastores y esta tiene su eje en el Misterio de la Eucaristía de la cual son constituidos ministros, ya que desde la Eucaristía, brota la transmisión de la fe, la celebración del misterio cristiano, y el servicio al mundo en la caridad (lex credendi, lex orandi, lex vivendi). Somos conocedores de que al sacerdote le ha sido dada una «potestad espiritual» en orden a llevar a los hombres a la «madurez cristiana» (PO 6) y también sabemos que eso necesariamente tiene que ver con el corazón de la vida eclesial que es la Eucaristía. Por eso decimos que la felicidad sacerdotal, la vitalidad apostólica depende en gran medida de la toma de conciencia de que la identidad sacerdotal está basada esencialmente en la paternidad espiritual del pastor y no en el puro activismo social como en tantas ocasiones puso de manifiesto Juan Pablo II y actualmente el mismo Benedicto XVI. 
Dejemos ahora hablar al Maestro Ávila para que nos diga cómo ha de ser el sacerdote de todos los tiempos capaz de superar los momentos de tribulaciones cultural, social y eclesial que estamos pasando.

\section{ORIGEN DEL SER Y QUEHACER SACERDOTAL}

El sacerdote, según el apóstol de Andalucía, se define por ser el hombre que testimonia el amor divino, lo celebra y lo proclama, de tal manera que «sienta como propios suyos los trabajos y pecados ajenos, representándolos delante del acatamiento de la misericordia de Dios con afecto piadoso y paternal corazón; el que debe tener el sacerdote con todos a semejanza del Señor, y también de San Ambrosio, que decía que no menos amaba a los hijos espirituales que tenía que si los hubiera engendrando de legítimo matrimonio; y San Juan Crisóstomo dice que aún se deben amar mucho más. Y así, el nombre de padre que a los sacerdotes damos les debe de amonestar que, pues no es razón que lo tengan en vano y mentira, deben de tener dentro de sí el afecto paternal y maternal para aprovechar, orar y llorar por sus prójimos» ${ }^{4}$. De manera que para Ávila, si «Dios nos ama con amor de padre, madre y esposo» $»^{5}$, el ministerio sacerdotal ha de ser la presencia privilegiada de ese amor de Dios a los hombres ${ }^{6}$.

\section{Desposado con la misión del «Dios Humanado»}

Toda la vida sacerdotal arranca del significado que tiene la encarnación del Verbo. Es aquí donde el sacerdocio de Cristo aparece como unos desposorios con la humanidad para que, por «amor y sacrificio», ésta sea agradable al Padre. De esta manera, nuestro autor, explicita maravillosamente la entrega total del Sumo Sacerdote Cristo a la misión encomendada por el Padre. De igual modo, los sacerdotes por la participación en el sacerdocio de Cristo se han desposado con la misión de "encaminar las ánimas para el cielo. Sicut misit me Pater, et ego mitto vos» ${ }^{7}$. La vida del sacerdote está sellada por el sentido del misterio de la encarnación del Verbo, ellos serán instrumentos de la gracia y de la santidad que ha venido a comunicarnos el Dios Humanado. Y así, ellos (los sacerdotes) ofrecen su «fragilidad y Dios su grandeza» ${ }^{8}$.

4. Obras Completas de San Juan de Ávila, Nueva edición crítica, 4 vols., Madrid 20002003. Citaremos de la manera siguiente: catalogación o título del escrito (si hay duplicidad se indica entre paréntesis con cifra arábiga), luego con números romanos señalamos el volumen, y, por último, la página en arábiga. Tratado sobre el sacerdocio, I, 917.

5. Tratado del amor de Dios, I, 951.

6. «El sacerdote, como Orígenes dice, es faz de la Iglesia; y como en la faz resplandece la hermosura de todo el cuerpo, así la clerecía ha de ser la principal hermosura de toda la Iglesia»: Tratado sobre el sacerdocio, I, 917.

7. Pláticas, I, 852; Cf. Carta 35, IV, 190.

8. Cf. Ib. 787-788. 
Con razón, la espiritualidad sacerdotal avilista puede ser llamada «espiritualidad de la encarnación», ya que el sacerdote es "un desposado con las almas» a imitación de la entrega del Verbo humanado. Así, en la contemplación de la donación de la interioridad sacerdotal del Hijo en el acontecimiento de su encarnación, hay una criatura privilegiada que es María. Ella es considerada, por Ávila, como Madre y Esposa de Cristo Sacerdote y a la vez aparece como Madre de los sacerdotes. Es el modelo espiritual de respuesta y colaboración en el sacrificio redentor de Cristo. La misión de ser «coadiutores Dei» se aplica tanto a María como a los sacerdotes ${ }^{9}$. De aquí se deriva la fuerte nota mariana que impregna la paternidad de los sacerdotes, porque, como se diría en términos actuales, María representa para Ávila «el rostro materno de Dios» ${ }^{10}$.

\section{Sed padres a semejanza del Señor}

La tarea sacerdotal es similar a la de un padre que engendra, ayuda a crecer, educa y alimenta a su prole. Así, la paternidad espiritual sacerdotal nace del oficio eucarístico para el cual hemos sido ordenados y que es «fuente y culmen de toda evangelización» (PO 5). En nuestra ordenación sacerdotal se nos entregó el pan sobre la patena y el cáliz con el vino, y se nos dijo: «Recibe la ofrenda del pueblo santo. Para presentarla a Dios. Considera lo que realizas e imita lo que conmemoras y conforma tu vida con el misterio de la cruz del Señor» ${ }^{11}$.

El concilio de Florencia (1438-1445) afirma que el sacerdote «recibe la potestad de ofrecer el sacrificio en la Iglesia, por los vivos y por los difuntos» (DS 701). Trento habla del presbiterado en relación con la potestad de «consagrar y ofrecer el verdadero cuerpo y sangre del Señor y de perdonar los pecados» (DS 961). El Vaticano II plantea las funciones del presbítero como ministro de la Palabra, de los sacramentos y de la eucaristía, y como rector del pueblo de Dios (PO 4-6). Así, el sacerdote participa de la autoridad de Cristo en «hacer crecer, santificar y gobernar el propio cuerpo» (PO 2). Actuando en «nombre de Cristo, cabeza de la Iglesia», «modela y dirige al pueblo sacerdotal, efectúa el sacrificio eucarístico ofreciéndolo a Dios en nombre de todo el pueblo» (LG 10).

En el pensamiento avilista, la idea de sacerdote es esencialmente dinámica, como reflejan estos concilios. Proyecta el misterio de Cristo Sacerdote en el obrar y vivir de quienes han sido constituidos sacerdotes por el «único Pontífice» ${ }^{12}$.

9. «Mirémonos de pies a cabeza, ánima y cuerpo, y vernos hechos semejables a la sacratísima Virgen María, que con sus palabras trujo a Dios a su vientre... Y el sacerdote le trae con las palabras de la consagración»: Pláticas, I, 790. «Ella engendró a Cristo pasible, mortal y que venía a vivir en pobreza, humildad y desprecio; y ellos consagran a Cristo glorioso, resplandeciente, inmortal, impasible... se viene a encerrar en la pequeñez de la hostia y a las manos del sacerdote por medio de las palabras de la consagración»: Tratado sobre el sacerdocio, I, 908.

10. Ib., 928.

11. Pontifical Romano, Ordenación de presbíteros (versión española), Madrid 1997, 135.

12. Pláticas, I, 804. 
La misión de Cristo Sacerdote era la gloria de Dios y la salvación de las almas. Esto mismo queda impreso en el ministro de la Iglesia mediante el carácter sacerdotal que recibe en la Ordenación. De forma que «los sacerdotes... en la Misa nos ponemos en el altar en persona de Cristo a hacer el oficio del mismo Redentor, y hacémonos intercesores entre Dios y los hombres para ofrecer sacrificio» ${ }^{13}$. Para el Apóstol de Andalucía, el estar sacramentalmente «configurado» con Cristo y ser «signo» de Él ante los hombres, hace que ello sea fuente de actitudes básicas para el sacerdote.

La «repraesentatio Christi» no es un privilegio personal, sino que ha de estar integrada en el cuerpo social de la Iglesia. Es así que «la clerecía ha de ser la principal hermosura de toda la Iglesia» ${ }^{14}$, «de manera que si está el lego en pecado, ha de ser el eclesiástico tantos rayos de luz que alumbre las tinieblas de aquel cristiano que está en pecado» ${ }^{15}$. Y ello porque «oficio público tenéis, no tengáis corazón particular... no es el pueblo ordenado para vuestro provecho, mas vosotros para el pueblo» ${ }^{16}$. De aquí se deriva que el tan tratado tema de la dignidad sacerdotal no lo entienda como sinónimo de privilegio de clase, que reflejase una teología del "sacerdote-señor», sino todo lo contrario: es un reclamo a la santidad de vida y a una entrega a la misión encomendada. Quienes olvidaron la dignidad que conlleva la paternidad sacerdotal «muchos males han traído a la cristiandad»... Estos tales entendieron que la dignidad era «apacentarse a sí mesmo, buscando sus intereses y regalos, sin tener cuidado de curar las ovejas enfermas... dice que no había pastor; porque, para el pueblo, todo es uno no haberlo y ser descuidado» ${ }^{17}$.

Así como la fe en Dios Padre que nos ama en Cristo Sacerdote lleva al establecimiento de una fraternidad universal, de igual modo la paternidad espiritual del sacerdote ha de crear la comunión fraterna entre los cristianos, de los sacerdote entre sí y de éstos con sus obispos pues que estos han de ser modelo de la paternidad espiritual del sacerdote: «pues prelados con clérigos son como padres con hijos y no señores con esclavos, prevéanse el Papa y los demás en criar a los clérigos como hijos, con cuidado que pide una dignidad tan alta como ha de recibir, y entonces tendrán mucha gloria en tener hijos sabios y muchos gozo y descanso en tener buenos hijos, y gozar a toda la Iglesia con buenos ministros... Y éste es el punto principal del negocio y que toca en lo interior de él; sin lo cual

13. Tratado sobre el sacerdocio, I, 916.

14. Ib. Su concepción del sacerdote está fuertemente vinculada a la eclesiología, cosa que para algunos autores falta en Trento a la hora de abordar el sacramento del Orden.

15. Lecciones sobre 1S. Juan (1), II, 129.

16. Obsérvese que este texto dirigido a los gobernantes de Utrera (Sevilla) encierra tal visión teológica, que se puede aplicar a los eclesiásticos: Carta 86, IV, 366.

17. Causas y remedios de las herejías, II, 528. Véase la influencia de S. Agustín, Sermón 46, 3-30: PL 38, 273-288. Muy lejos de la concepción medieval que acentúa el sistema beneficial: «offitium-benefitium». Para Ávila, como para Domingo de Soto, el «offitium» era lo sustancial y nunca debía ocupar el primer plano del pastoreo sacerdotal el «benefitium» de la grey. 
todo trabajo que se tomare cerca de la reformación será de muy poco provecho, porque será, o cerca de cosas exteriores, o, no habiendo virtud para cumplir las interiores, no dura la dicha reformación por no tener fundamento» ${ }^{18}$.

De esa paternidad episcopal y presbiteral dimana la clave de la auténtica reforma del clero y del mismo pueblo de Dios, de tal manera que «cabeza y miembros nos juntamos a una en Dios, seremos tan poderosos, que venceremos al demonio en nosotros y libraremos al pueblo de los pecados... Así hizo Dios tan poderoso el estado eclesiástico, que, si es el que debe, influye en el pueblo toda virtud, como el cielo influye en la tierra» ${ }^{19}$.

Ahora bien, esa figura del sacerdote como padre, pastor, esposo y amigo de la grey está repleto de elementos agapetónicos, ya que para Ávila, «todo es negocio de amor» y, por tanto, cuando los sacerdotes están «revestidos del amor», saben crear comunión a todos los niveles y hacen realidad «creciendo cada uno, todos crecemos; $y$, aprovechando uno, todos aprovechan crecemos por la hermandad que todos tenemos» ${ }^{20}$.

\section{La paternidad sacerdotal en el ejercicio del triple «munus»}

En los años en torno a Trento, abundaban los escritos sobre el ejercicio del ministerio y la santidad sacerdotal, como exigencia para una renovación eclesial $^{21}$. Como otros reformadores de su tiempo, en Ávila encontramos ampliamente tratada la santificación de los sacerdotes en el ejercicio de su triple función que siglos más tarde se vería consagrado en el Vaticano $\|^{22}$. Desde la teología de Cristo Sacerdote, Buen Pastor, va a ir explicado cada uno de los oficios del sacerdote, el cual no ha de actuar como «funcionario», sino que, con «corazón de padre y madre», ha de apacentar a los fieles «en los pastos de ciencia y doctrina... y aunque sea con derramar sangre y dar la vida, como hizo Cristo, y dijo que éste tal es el Buen Pastor» ${ }^{23}$.

El eminente predicador de Andalucía se sentía llamado para una doble misión: «humillar al hombre y glorificar a Cristo» ${ }^{24}$. Esto lo realizará mediante el ministerio de la Palabra, para ello será «pregonero», «mensajero», «notario» y «embajador» del único misterio salvador que es Cristo Sacerdote. «Así como

18. Memorial primero al concilio de Trento, II, 487.

19. Pláticas, I, 795.

20. Lecciones sobre 1 San Juan (2), II, 357.

21. Esquerda BifEt, J., Diccionario de San Juan de Ávila, Burgos 1999, 816.

22. Para ver la actualidad de la doctrina de nuestro autor puede compararse la triple función de la que habla el Vaticano II (LG, 28; PO, 1-2), con la que desarrolla el Maestro Ávila. Se podrá observar una gran coincidencia de planteamientos.

23. Advertencias al concilio de Toledo, II, 650. «Y porque hubiese más voces que predicasen y más médicos que curasen las ánimas, aunque Él solo lo podía hacer, quiso tomar ayudadores... para curar ánimas... entrañas de padres...»: Sermón 81, III, 1084.

24. De Granada, L., Vida del Padre Maestro Juan de Ávila y las partes que ha de tener un predicador del evangelio, Barcelona 1964, 76. 
nos hizo hijos siendo Él Hijo, y sacerdote siendo Él Sacerdote, hízonos Él... palabra viva y eficaz para dar vida a los que la oyeren ${ }^{25}$.

Para el anuncio de tan gran Misterio, el predicador ha de estar «templado antes de subir al púlpito», con particular «disposición y santificación», «pues el oficio de predicador es de mayor peligro y pide mayor santidad ${ }^{26}$. Porque no se «engendra hijos con palabra pomposa y compuesta», más bien ofreciendo la vida a Dios por aquellos que escucharan su «voz», cuyo «sonido» es el «amor vivido» ${ }^{27}$.

La espiritualidad sacerdotal avilista tiene un fuerte acento eucarístico; no en vano, nuestro autor es conocido como el «apóstol de la eucaristía». Esto lo vemos en el ejercicio de la paternidad sacerdotal en el segundo «munus». Su quehacer como «un buen padre de una familia» es «amansar a Dios cuando estuviese enojado con su pueblo» ${ }^{28}$, mediante «la oración santa y el consagrar y ofrecer el cuerpo de Jesucristo» ${ }^{29}$. Por ello, es un oficio que pide "particular trato y amistad» con el Señor como «ejercicio, costumbre, apartamiento de cuidados y santidad de vida ${ }^{30}$. A pesar de esta insistencia en la santidad de los ministros, Ávila afirma que la gracia no depende de los «administradores de las cosas santas», pues «estaría en gran manera incierta la Iglesia, si hubiera de estar atada a saber si el ministro estaba en gracia o no, para hacer lo que su oficio demanda» ${ }^{31}$. El «amor del buen Padre Dios» está por encima de las deficiencias de sus ministros.

El deber de orar por los hombres no sólo deriva de la particular configuración con Cristo Sacerdote, sino también en cuanto el presbítero ha sido constituido en «atalaya» y «ojos de la Iglesia». De ahí que su «oficio sea llorar los males que vienen al cuerpo ${ }^{32}$. Es decir, todas las preocupaciones y problemas de los «espirituales hijos» son asumidos por el «corazón de madre de los sacerdotes» ${ }^{33}$.

La función de "ordenar y gobernar» a la grey es un servicio ante todo en la caridad. Por ello dirá: Sacerdotes, «mirad las pisadas del pastor» porque «las veces tenéis de Aquél que, por ser Buen Pastor, murió por el pro de sus ovejas; pareced en el amor a Él, pues parecéis en la dignidad ${ }^{34}$. Cristo es la «caridad del Padre» que «ha trasplantado esta caridad del cielo a la tierra» ${ }^{35}$. La caracte-

25. Carta 1, IV, 5ss. dirigida a Fr. Luis de Granada, O.P.

26. Reformación del estado eclesiástico, II, 494.

27. Carta 1, IV, 7-8. Cf. Gallego Palomero, J. J., San Juan del Ávila, modelo de praxis ministerial, en URÍBARRI, G., dir., El ser sacerdotal. Fundamentos y dimensiones constitutivas, Madrid 2010, 401-403.

28. Pláticas, I, 793.

29. Tratado sobre el sacerdocio, I, 911.

30. Pláticas, I, 805. Cf. Tratado sobre el sacerdocio, I, 918-919.

31. Lecciones sobre 1 San Juan (2), II, 352.

32. Tratado sobre el sacerdocio, I, 915

33. Ib., 917.

34. Carta 86, IV, 369. La imagen del Buen Pastor es riquísima en el Maestro Ávila y es la base teológica de sus Memoriales para Trento, llevados por el Arzobispo de Granada Pedro Guerrero al aula conciliar.

35. Lecciones sobre 1 San Juan (2), II, 352. 
rística del pastoreo de Jesucristo es el amor sin medida, en cuanto que es «corazón del Padre» y ha sido constituido en «Médico y Pastor amoroso» que, con «el rocío de su gracia», "obra en sus ovejas todo lo que obró por las calles, plazas y templo de Jerusalén... sanando lo enfermo, esforzando lo flaco, guardando lo sano, buscando lo perdido y trayéndolo al rebaño». «Este Señor, por ser Dios, es dueño de las ovejas, pues las crió con el Padre y con el Espíritu Santo. Y llámese siervo del Padre en cuanto hombre, porque le sirvió y obedeció en la obra de la Redención de los hombres» ${ }^{36}$. Ésta es la caridad que deben encarnar aquellos que han recibido de la Iglesia la misión de «apacentar el rebaño de Cristo». Para ello se requiere en el pastor «ferviente y eficaz oración y también santidad $»^{37}$. Esta tarea ha de llegar a todos, pero especialmente a los más pobres porque no derramó Cristo su sangre «más por el rico que por el pobre, ni por el rey que por el esclavo; igualmente derramó la sangre por todos» ${ }^{38}$.

\section{Paternidad sacerdotal y consagración por vida}

Por el sacramento del Orden, el sacerdote ha quedado todo entero consagrado al Señor, tanto en el ser, como en el obrar y en el sentir, de manera que la vida de un presbítero ha de ser «un holocausto quemado en honor de Dios» ${ }^{39}$. De ahí que la paternidad del sacerdote no es «hoy sí, pero mañana no», o algo accidental en un determinado momento pastoral, sino que deviene de la acción del Paráclito que opera en el sacramento recibido e introduce en el corazón del ordenado «la forma y similitud suya, que es la caridad y gracia, con que nos enciende y santifica ${ }^{40}$. Aquellos que han sido sacramentalmente configurados con Cristo Sacerdote han de llevar una vida semejante a la de Él, de tal manera que sean "carta de Cristo», "buen olor suyo», "hermosura de la Iglesia», ya que la paternidad espiritual del sacerdote, a semejanza de la de Dios Padre es:

Carta que la saben y leen todos, porque cualquier gente, por bárbara que sea, aunque no entiende el lenguaje de la palabra, entiende el lenguaje del buen ejemplo y virtud, que ve puesto por obra, y de allí vienen a estimar en mucho al que tales discípulos tiene ${ }^{41}$.

El Verbo humanado se despojó de su rango y se hizo «carne limpia», «amador de pobreza» y «varón obediente», igualmente quienes participan de su Sacerdocio ministerial han de estar marcados en su forma de vida, porque se han «des-

36. Sermón 54, III, 707.

37. Tratado sobre el sacerdocio, I, 941.

38. Lecciones sobre 1 San Juan (1), II, 183.

39. Pláticas, I, 800.

40. Dialogus inter confessarium et paenitentem, II, 785. «¿De qué manera? Vive en mí Jesucristo por humildad, por caridad y por gracia, y donde esta gracia llega, hace mudar al hombre al revés de como estaba»: Sermón 32, III, 403.

41. Audi filia (2), I, 612. 
posado» en pobreza, castidad y obediencia, «de tal manera que, de día y de noche, todos sus pensamientos, amor y deseos no se ejerciten sino en Cristo» ${ }^{42}$. Así, como Dios se entregó totalmente a la humanidad, el sacerdote ha de estar consagrado enteramente a «las cosas santas» y «al bien de las ánimas».

El presbítero es verdaderamente pobre como Cristo cuando es de «hecho y de corazón ${ }^{43}$, cuando su elección de las personas y de las cosas no ha sido según los cánones del mundo ${ }^{44}$. La pobreza, tanto personal como comunitaria, será para Ávila un arma para enfrentarse a las herejías de su tiempo y a la vez un estímulo para todos «a ser santos como el Padre celestial es Santo» ${ }^{45}$.

El celibato y la castidad son «dádiva graciosa de Dios» ${ }^{46}$ que viene reclamada por la novedad del sacerdocio inaugurado en Cristo. Son requeridos no solamente por la relación con la Eucaristía, sino también por la misión, porque «mal podrían militar a Dios y a negocios seculares... , ¿qué harían si cargasen de los cuidados de mantener mujer y hijos, casarlos, y dejarles herencia?» ${ }^{47}$.

Mientras que el voto de castidad «limpia el corazón de la afición carnal», la obediencia «limpia el alma de las desordenadas aficiones espirituales» ${ }^{48}$. Las relaciones de obediencia en la Iglesia están marcadas por la caridad «pues prelados con clérigos son como padres con hijos y no señores con esclavos»" ${ }^{49}$. "Porque el mandar es cosa fácil y sin caridad se puede hacer; mas llevar a cuestas flaquezas ajenas con perseverante corazón de las remediar e hacer fuerte al que era flaco, pide riqueza de caridad $\iota^{50}$. Por parte del sacerdote a su obispo ha de haber «humildad» y «buen obedecer». Pues para que haya «un buen obedecer» ha de haber «unos superiores que trabajen para que sus súbditos sean tales» ${ }^{51}$, ya que «quien a hombres ha de regir, más que hombre ha de ser» ${ }^{52}$.

42. Cartas 224, IV, 715. Siguiendo la línea patrística (Ireneo, Cipriano, Ambrosio...) pedirá una amplia gama de virtudes (simplicidad, esperanza, caridad...), pero sobre todo en la pureza: inocencia, conciencia pura, conducta íntegra e intachable, limpieza de alma y cuerpo.

43. Cf. Carta 224, IV, 715-716.

44. «Por cierto, hermanos, si lo que el mundo escoge es lo mejor, Jesucristo se engañó y escogió lo peor. Él no puede ser engañado... pues Él no puede errar y escogió la pobreza, trabajos y cruz, que aquello es lo mejor, y lo contrario, por mucho que el mundo elija y lo aprecie, es lo peor»: Sermón 71, III, 976.

45. Cf. Reformación del estado eclesiástico, II, 500-502; Causas y remedios de las herejías, II, 608-612. Trento no olvidó el tema de la pobreza de los eclesiásticos que tanto preocupó a nuestro autor. Así en el primer canon de reforma (18 de noviembre de 1563), se trató la influencia positiva que la austeridad de vida de los pastores ejerce en los fieles: CT 9, 1033.

46. Audi filia (1), 1, 415.

47. Causa y remedios de las herejías, II, 608-612.

48. Carta 224, IV, 721.

49. Reformación del estado eclesiástico, II, 487.

50. Ib., II, 487.

51. Ib., II, 486.

52. Carta 11, IV, 73. En esta interesante carta acerca del ejercicio de gobernar dice en otro lugar: «El oficio público cruz es, y desnudo de todos los afectos propios y vestido del amor de los muchos ha de estar el que en esta cruz hubiera de subir, para imitar al Hijo de Dios y que su cruz sea provechosa para sí y para los otros» $(I b ., 77)$. 


\section{SER ECLESIAL, PERO NO CLERICAL}

Juan de Ávila es un hombre de matices que hay que saber descubrir en sus escritos para no caer en valoraciones reduccionistas. Su concepción del sacerdote está fuertemente vinculada a la eclesiología, cosa que para algunos autores falta en Trento a la hora de abordar el sacramento del Orden. Así, solamente desde la primacía del amor en la vida cristiana y sacerdotal, es como se adquiere el verdadero sentido de Iglesia, y se entiende en su justo término las normas o consejos ascéticos de nuestro autor.

... porque hay una Compañía, la cual llamamos Iglesia, en la cual todos los bienes son comunes... tienen fundamento que son los apóstoles... Tienen capitán, que es Jesucristo... , llamase también esta Compañía Cuerpo... , nunca crece la Iglesia sino en caridad... A esto vino el Hijo de Dios del cielo, a trasplantar esta caridad del cielo a la tierra ${ }^{53}$.

Por eso mismo, no podemos olvidar que la paternidad espiritual del sacerdote se da en el seno de una comunidad llamada Iglesia. En toda circunstancia y en la actualidad mucho más, la Iglesia resulta incómoda al mundo porque ésta llama a los hombres a la verdad y recuerda que ninguna forma de poder puede ser la respuesta adecuada a las exigencias más profundas del corazón humano. Los sacerdotes son los predicadores de la verdad de Cristo frente a la mentira del mundo, por eso mismo ellos son en muchos casos los primeros que reciben el rechazo de esta «sociedad sin padre». Ellos, por el sacramento del orden, han sido constituidos en servidores de la paternidad de Dios y de la maternidad de la Iglesia. Por eso para el Maestro Ávila hay que vivir el sacerdocio en clave del verdadero discipulado donde: «ningún siervo es superior a su señor. Si el mundo os odia, recordad que primero me odió a mí. Si pertenecierais al mundo, el mundo os amaría como cosa propia; pero yo os elegí y os saqué de él, por eso el mundo os odia» (Jn 15, 18-20), pero "¿Quién es el que vence al mundo, sino el que cree que Jesús es el Hijo de Dios? Todo el que ha nacido de Dios vence al mundo; y ésta es la fuerza victoriosa que ha vencido al mundo: nuestra fe» (1 Jn 5, 4-5). La dimensión eclesial de la espiritualidad sacerdotal avilista es una consecuencia lógica de su marcado cristocentrismo. La «repraesentatio Christi», como ya hemos dicho, no es un privilegio personal, sino que ha de estar integrada en el cuerpo social de la Iglesia ${ }^{54}$. De ahí, que «oficio público tenéis, no tengáis corazón particular... No es el pueblo ordenado para vuestro provecho, mas vosotros para el del pueblo» ${ }^{55}$.

53. Lecciones sobre 1 San Juan (2), II, 350-357.

54. Cf. Tratado sobre el sacerdocio, I, 916.

55. Obsérvese que este texto dirigido a los gobernantes de Utrera (Sevilla) encierra tal visión teológica que se puede aplicar a los eclesiásticos: Carta 86, IV, 369. 
El ser eclesial del presbítero se manifiesta en primer lugar en su actitud vigilante sobre la heredad del pueblo apacentado: «porque vendrá el tiempo en que los hombres no soportarán la sana doctrina, sino que llevados de su propia concupiscencia, se rodearán de multitud de maestros que les dirán palabras halagadoras, apartarán los oídos de la verdad y se volverán a las fábulas» (2 Tim 4, 3). Esta vigilancia no sólo en la «sana doctrina» (lex credendi), sino también en el tesoro que significa la «Divina Liturgia» (lex orandi) para que el pueblo vuelva a los templos a gustar su riqueza en la celebraciones de «los santos misterios» realizados como la Iglesia quiere y desea celebrar, evitando una liturgia hecha a desgana y dejadez o bien convertida en algo redundante y excesivo pensando que con ello hay más misterio o espiritualidad ${ }^{56}$.

Un segundo aspecto sería iniciar al cristiano en el gusto por aquellos textos o lecturas de la tradición cristiana que a lo largo de la historia han forjado los grandes testigos del evangelio y que son piezas claves para la vida espiritual. El sacerdote es como el padre de familia que sabe sacar lo antiguo y lo nuevo del arca para alimentar a los fieles que ha de pastorear en el conocimiento y degustación de los testimonios de los Padres de la Iglesia, de los grandes pensadores y teólogos, de los santos y los mártires que dieron la vida por Jesucristo. Para llevar esto a cabo fundará colegios especiales para formar buenos predicadores de la palabra que «engendre» hijos espirituales por la predicación y la enseñanza ${ }^{57}$.

Por último, para el Maestro Ávila la educación en la vida comunitaria, que no se agota en una formula o modelo pastoral. Participando en los gestos comunitarios, la persona es introducida sin darse cuenta en una forma de vida netamente cristiana (lex vivendi). En fin, en esta compañía llamada Iglesia quienes sientan el deseo o la necesidad del consejo espiritual, podrá encontrar en el sacerdote la referencia más sacramental que la Iglesia a puesto para el bien y la salvación de las almas: el sacramento de la Penitencia. Este sacramento de la Reconciliación ha de estar integrado en la vida personal de cada presbítero. El sacerdote que no se siente asiduamente penitente y celebra sacramentalmente el Perdón, difícilmente será un verdadero padre y pastor. El Patrono del clero secular es un gran ejemplo a seguir, por ello decía Luis Muñoz: «Al terminar su sermón, que de ordinario duraba dos horas, cansado y muchas veces enfermo, sin tomar alimento se iba derecho al confesionario y escuchaba pacien-

56. Cf. Sermones 35-37, III, 429-512; Pláticas, I, 855-862; Advertencia al concilio de Toledo, II, 717-722; Cartas 217 y 233, IV, 689; 745-747; Advertencia al Concilio de Toledo, II, 721-722; Miscelánea breve, II, 861-865; Causa y remedios de las herejías, II, 600-603; Sermones 35 al 37, III, 429-512; Causas y remedios de las herejías, VI, 170-171; Reformación del estado eclesiástico, II, 510; Causas y remedios de las herejías, II, 597-598; Cartas 11 y 179, IV, 83-84; 593-595; Causas y remedios de las herejías, II, 578-588; Advertencia al Concilio de Toledo, II, 688-689; Causas y remedios de las herejías, II, 599-601.

57. Véase Tratados de reformas; Carta 1, IV 5-14. Cf. Gallego PalomeRo, J.J. Sacerdocio y oficio sacerdotal en San Juan de Ávila. Córdoba 1988, 227-229; DEL CAMPo GuIRALTE, M., "San Juan de Ávila, catequista», Toletana 10 (2004) 119-124. 
temente a cuantos se le acercaban, continuando en esta ocupación sin preocuparse de la comida hasta las 5 o 6 de la tarde, sin mostrar cansancio y recibiéndolos con gran afabilidad y dulzura» ${ }^{58}$.

Cuando él Apóstol de Andalucía habla del «desprecio del mundo» tiene presente el significado joánico de «la soberbia de la vida, codicia de la carne y codicia de los ojos». Por lo tanto, la entrega absoluta a la salvación de las almas lleva al sacerdote-apóstol a situarse en su exacta medida ante el mundo, sin caer por un lado en ningún angelismo sobre la condición humana, pero por otro lado, tampoco sucumbir en un pesimismo sobre la creación. Cristo es la «caridad del Padre» que «ha trasplantado esta caridad del cielo a la tierra» ${ }^{59}$.

Como ya hemos visto, en la doctrina avilista encontramos el axioma de que «según el sacerdote, así el pueblo». El testimonio de vida es, para Ávila, casi un «munus» sacerdotal, ya que el presbítero con la honestidad y santidad en su ministerio ha de «provocar a otros servir a Dios». Frente al fideísmo protestante que por aquel entonces comenzaba a despuntar, para el Patrono del clero diocesano español no hay testimonio de vida sacerdotal que no pase por la unión y cooperación con el «sucesor de Pedro» y con «los sucesores de los apóstoles». El Maestro Ávila afirmará que no basta decir que seguimos a Cristo, sino que es menester ir detrás del hombre señalado por Él, puesto para «confirmar la fe a todos los otros», para «fundar leyes y mandar costumbres, que con los tiempos se mudan». "Quién de los eclesiásticos osará vivir como quiere viendo a su príncipe vivir vida de cruz por bien de la Iglesia» ${ }^{60}$. Y esto lo afirmaba en una situación eclesial en que Papas y Obispos y demás dignidades dejaban mucho que desear. Así sus biógrafos inmediatos (Fr. Luis de Granada y Lic. Luis Muñoz) nos relatan cómo se dio en Ávila y sus discípulos esta unión y cooperación con el obispo y entre los sacerdotes, de modo que podemos hablar de la llamada «escuela sacerdotal avilista», cuyos miembros se distinguían por su fuerte vida interior, por el gran celo apostólico y por una estrecha «communio ecclesialis», siendo estos sacerdotes estímulo de santidad para el pueblo de Dios ${ }^{61}$.

A MODO DE CONCLUSIÓN: DECÁLOGO PARA VIVIR LA PATERNIDAD ESPIRITUAL DEL SACERDOTE EN CUALQUIER TIEMPO Y LUGAR

1. El sacerdote ha de poseer un propio conocimiento de lo que él es ${ }^{62}$.

2. Ha de tener una triple mirada: a Dios, a los hombres, y así mismo ${ }^{63}$.

58. Biografía, I, 245ss.

59. Lecciones sobre 1 S. Juan (2), II, 352.

60. Causas y remedios de las herejías, II, 565-569.

61. Cf. Esquerda BIFET, J., «Escuela sacerdotal española del siglo XVI: Juan de Ávila (1499-1569)», Anthologica Annua 17 (1969) 45-55.

62. «De la gran maldad de nuestro corazón y la raíz de nuestros males», Sermón 69 III, 933.

63. Cf. Audi filia (1), I, 462. 
3. Deberá apreciar el haber sido elegido para tan «alto oficio» ${ }^{64}$.

4. Recordará e imitará la Pasión de Cristo en su vida ${ }^{65}$.

5. Sentirá con la Iglesia, porque es "guardián de la viña» ${ }^{66}$.

6. La «sana doctrina» que dará al pueblo será fruto de la oración y del conocimiento de las Escrituras, de los Padres y de la Teología ${ }^{67}$.

7. En la comunión eclesial se requiere siempre «humildad y obediencia» ${ }^{68}$.

8. Llevará una vida austera, ya que el sacerdote «holgado no es de Cristo» ${ }^{69}$.

9. Se despojará de afectos humanos y de la búsqueda de honra e intereses personales ${ }^{70}$.

10. Testimoniará con su vida las obras del Espíritu, para así mejor «ganar almas a Dios» ${ }^{71}$.

Gran razón tenía el Papa Pablo VI cuando el día de la canonización de nuestro autor declaró que: «San Juan de Ávila es un sacerdote, que bajo muchos aspectos podemos llamar moderno». Siguiendo su modelo y doctrina los sacerdotes del siglo XXI vivirán con alegría lo esencial de su sacerdocio que no es otra cosa que ser «hombres de Dios que engendran como padres almas para Cristo». Esto será el mejor revulsivo para superar la crisis sacerdotal que vivimos en esta época de turbaciones.

64. «Pues, cuando nosotros entendamos que está sobre nuestros hombros la carga de nuestros pecados... y la de nuestro pueblo, y, la de todo el mundo, entonces comenzaremos a sentir qué cosa es sacerdote», Pláticas, III, 392.

65. «Los que predican reformación de Iglesia, por predicación e imitación de Cristo crucificado lo han de hacer y pretender», Pláticas III, 409-410; Cf. Audi filia (2), I, 750; Lecciones sobre 1 S. Juan (1), IV, 237-251; DE VILLAR, B. La abnegación en los escritos del Beato Juan de Ávila, Madrid 1959.

66. Causas y remedios de las herejías, VI, 94.

67. Cf. Ib., 108. 144-166.

68. Pláticas, I, 794-795.

69. Sermón 73, III, 994; Cf. Pláticas, I, 852; Cartas 178, IV, 591.

70. Cf. Sermón 81, III, 1084-1085; Pláticas, I, 899; Cartas 182, IV, 601.

71. Cf. Sermones 60, 62, 75, III, 801, 822, 1001. 